\title{
Suscetibilidade de cultivares de algodoeiro a Rhizoctonia solani e benefícios do tratamento de sementes com fungicidas
}

\author{
Augusto César Pereira Goulart
}

Embrapa Agropecuária Oeste - Caixa Postal 661 - CEP: 79804-970 - Dourados, MS, e-mail: goulart@cpao.embrapa.br. Trabalho financiado pela Fundect Data de chegada: 08/03/2005. Aceito para publicação em: 07/02/2007.

\section{RESUMO}

Goulart, A. C. P. Suscetibilidade de cultivares de algodoeiro a Rhizoctonia solani e benefícios do tratamento de sementes com fungicidas. Summa Phytopathologica, v.33, n.3, p.222-228, 2007.

Este trabalho teve por objetivo avaliar o comportamento de seis cultivares de algodoeiro (BRS-Ipê, BRS-Aroeira, BRS-Cedro, Fibermax 966, DeltaOpal e CNPA Ita 90-II) ao fungo Rhizoctonia solani AG-4 e os benefícios do tratamento de sementes de algodoeiro com fungicidas para cada cultivar em estudo, em relação à densidade de inóculo deste fungo. O ensaio foi conduzido na casa de vegetação da Embrapa Agropecuária Oeste, em Dourados, MS. Foram definidas quatro densidades populacionais do fungo $(0 ; 1 ; 2$ e $3 \mathrm{~g}$ de inóculo do fungo/ bandeja plástica de $56 \times 35 \times 10 \mathrm{~cm}$ ) para a realização do ensaio. As avaliações foram realizadas com base no desenvolvimento de sintomas e sobrevivência das plântulas, utilizando os dados de emergência inicial e final e de tombamento de pós-emergência. Sementes não tratadas e tratadas com a mistura fungicida tolylfluanid + pencycuron + triadimenol $(30+50+50 \mathrm{~g}$ do i.a. $/ 100 \mathrm{~kg}$ de sementes $)$ foram semeadas em areia contida em bandejas plásticas, dispostas em orifícios individuais, eqüidistantes e a $3 \mathrm{~cm}$ de profundidade. A inoculação com R. solani foi feita pela distribuição homogênea do inóculo do fungo na superfície do substrato. O fungo foi cultivado por 35 dias em sementes de aveia preta autoclavadas e trituradas em moinho $(1 \mathrm{~mm})$. Houve efeito significativo das interações cultivares x níveis de inóculo, cultivares $\mathrm{x}$ fungicidas e níveis de inóculo $\mathrm{x}$ fungicidas. $\mathrm{O}$ comportamento das cultivares foi significativamente influenciado pelas diferentes populações de $R$. solani, sendo que, a medida que se aumentou a densidade de inóculo do patógeno, menores índices de emergência e maiores índices de doença foram observados. Ficou claramente demonstrada também a importância do tratamento das sementes de algodoeiro com fungicidas, sendo que as melhores emergências e os menores índices de doença (tombamento e plântulas lesionadas), independente da cultivar testada, foram obtidos quando as sementes foram tratadas com a mistura tolylfluanid + pencycuron + triadimenol. Observou-se ainda que as populações do patógeno influenciaram significativamente nos benefícios do tratamento de sementes, demonstrando que a performance da mistura fungicida testada (tolylfluanid + pencycuron + triadimenol) foi melhor na presença dos níveis mais baixos de inóculo do fungo. Com relação as cultivares avaliadas e na ausência do tratamento da sementes com fungicidas, observouse comportamento diferenciado de alguns materiais com relação ao ataque do fungo $R$. solani, merecendo destaque os genótipos CNPA ITA 90 II E BRS Aroeira, seguidas de BRS Cedro e BRS Ipê, demonstrando uma maior tolerância destas cultivares ao ataque de $R$. solani em comparação às demais.

Palavras-chave adicionais: tombamento, emergência, nível de inóculo, Gossypium hirsutum.

\section{ABSTRACT}

Goulart, A. C. P. Susceptibility of cotton cultivars to Rhizoctonia solani and benefits of fungicide seed treatment. Summa Phytopathologica, v.33, n.3, p.222-228, 2007.

The objective of this work was to evaluate the behavior of six cotton cultivars (BRS-Ipê, BRS-Aroeira, BRS-Cedro, Fibermax 966, DeltaOpal and CNPA Ita 90-II) in relation to Rhizoctonia solani AG4 and the benefits of cotton seed treatment with fungicides, for each tested cultivar, for the control of damping-off in relation to inoculum densities of this fungus. This experiment was carried out at greenhouse conditions at Embrapa Agropecuária Oeste, in Dourados, MS. Four inoculum densities were tested $(0 ; 1 ; 2$ and $3 \mathrm{~g}$ of fungus inoculum/ plastic tray with dimensions of $56 \times 35 \times 10 \mathrm{~cm})$ in the trial. The evaluations were done based on symptoms development and seedling survival, using initial and final emergence and pre and pos dampingoff data. Treated and untreated seeds with fungicides mixture tolylfluanid + pencycuron + triadimenol $(30+50+50 \mathrm{~g}$ a.i. $/ 100 \mathrm{~kg}$ of seeds) were sowed in sand contained in plastic trays, by placing in equidistant 3-cm-deep wells. The inoculation with $R$. solani AG-4 was done by the homogeneous distribution of the fungus inoculum onto the substrate. The fungus was grown for 35 days on autoclaved oat seeds and then ground to powder using a mill $(1 \mathrm{~mm})$. Significant effect of the interactions cultivars $\mathrm{x}$ inoculum densities, cultivars $\mathrm{x}$ fungicides and inoculum densities $x$ fungicides were oberved. The cultivars behavior was significantly influenced by different populations of $R$. solani. Results showed that the higher the inoculum density, the higher the disease level and the lower the emergence rates. It was also demonstrated the importance of cotton seed treatment with fungicides, with best results in relation to emergence and disease level (dampingoff and lesioned seedlings), regardless of tested cultivar, being obtained when the seeds were treated with tolylfluanid + pencycuron + triadimenol. It was still observed that pathogen population 
significantly influenced the benefits of seed treatment, since the performance of fungicides was better when inoculum densities were low. In the absence of seed treatment with fungicides, differences among the cultivars in relation to $R$. solani were observed, being distinct in CNPA ITA 90 II and BRS Aroeira, followed by BRS Cedro and BRS Ipê, which showed higher tolerance to $R$. solani.

Additional keywords: damping-off, emergence, inoculum level, Gossypium hirsutum.

Um dos principais problemas que os cotonicultores vem enfrentando atualmente tem sido o tombamento de plântulas causado por Rhizoctonia solani Kuhn grupo de anastomose (AG)-4 (teleomorfo: Thanatephorus cucumeris (A.B. Frank) Donk), de acordo com relatos de Davis et al. (3), Goulart et al. (9), Menten \& Paradela (15) e Wang \& Davis (16). Esta doença é repetidamente citada como a mais séria enfermidade que ataca o algodoeiro na fase inicial de desenvolvimento, podendo, freqüentemente, reduzir o estande e, em casos mais sérios, levar à ressemeadura, conforme Goulart (11).

Dentre as práticas recomendadas para o controle dessa doença, o tratamento de sementes é a tecnologia mais empregada e eficiente para este tipo de problema, o que a torna uma ferramenta estratégica dentro do contexto do manejo integrado de doenças $(3,8,10,16)$.

Nos EUA, vários estudos envolvendo benefícios do tratamento de sementes de algodoeiro com fungicidas em relação ao potencial de inóculo de $R$. solani no solo vêm sendo realizados $(3,7,8,16)$. No Brasil, até o momento, poucos estudos dessa natureza vêm sendo desenvolvidos como, por exemplo, aqueles realizados por Goulart $(12,13)$.

Sabe-se que a resistência genética é potencialmente o mais econômico e eficiente método de controle de doenças de plantas. Segundo Freire \& Farias (5), atualmente os programas de melhoramento que priorizam o desenvolvimento de cultivares a serem plantadas no Centro-Oeste do Brasil têm procurado desenvolver variedades com melhor nível de resistência às principais doenças do algodoeiro. Entretanto, em se tratando do tombamento de plântulas causado por $R$. solani, não se conhece nenhuma informação no Brasil que mostre o comportamento das cultivares disponíveis no mercado frente a ação desse patógeno. Nos USA, trabalhos desenvolvidos por Bush et al. (2), Garber et al. (6) e Hefner (14) mostraram diferentes respostas de cultivares de algodoeiro frente ao patógeno $R$. solani. Assim, Hefner (14) relata que apenas uma de dez cultivares de algodoeiro testadas mostrou boa emergência e bons níveis de sobrevivência na presença de $R$. solani. Wang \& Davis (16), relatam que a cultivar Maxxa foi a mais suscetível, apresentando, pelo menos, 50\% de tombamento de pré-emergência. Por outro lado, as cultivares DP 6100 , CB 7 e Royale apresentaram-se como as mais resistentes a $R$. solani, apesar das diferenças de performance destas cultivares terem sido geralmente pequenas.

Conforme DeVay et al. (4), estudos em casa de vegetação, visando determinar a performance de fungicidas aplicados em tratamento de sementes de algodoeiro, tem sido um indicador bastante útil para predizer a eficácia desses produtos a nível de campo. Esta mesma consideração é válida para estudos visando determinar a suscetibilidade de cultivares de algodoeiro a $R$. solani, conforme relatos de Bush et al. (2), Garber et al. (6), Hefner (14) e Wang \& Davis (16).

O objetivo deste trabalho foi avaliar o comportamento de seis cultivares de algodoeiro disponíveis no mercado frente a ação do fungo $R$. solani e os benefícios do tratamento de sementes de algodoeiro com fungicidas para cada cultivar em estudo.

\section{MATERIAL E MÉTODOS}

O ensaio foi conduzido na casa de vegetação da Embrapa Agropecuária Oeste, em Dourados, MS, no ano de 2003.

Para a produção de inóculo do patógeno, culturas puras de $R$. solani AG-4, isolado de lesões do coleto de plântulas de algodoeiro, foram mantidas em meio de cultura BDA contido em placas de Petri (previamente esterilizadas em Forno de Bier) por 48 horas, em estufas de incubação para BOD, por 5 dias, sob regime alternado de 12 horas de luz/12horas de escuro, a $22^{\circ} \mathrm{C}$, condições estas necessárias para o crescimento do patógeno. Após esse período, o fungo foi repicado para um substrato composto de $2 \mathrm{~kg}$ de sementes de aveia preta e 0,5 L de água, previamente autoclavado, em Erlenmeyer de 2,0 L, durante 30 minutos, por três dias consecutivos, a $127^{\circ} \mathrm{C}(1,5 \mathrm{~atm}$ de pressão) sendo mantido em condições ambientes por 35 dias. No $35^{\circ}$ dia, foi retirada do Erlenmeyer a aveia colonizada pelo fungo, a qual foi seca à sombra por dez dias. Ao final desse período, esse substrato (aveia + R. solani) foi triturado em um moinho ( $1 \mathrm{~mm}$ ), de modo a se obter o inóculo do patógeno, na forma de um pó.

Sementes de algodoeiro, deslintadas com ácido sulfúrico, foram semeadas em areia lavada, previamente autoclavada (por três vezes consecutivas), sendo cada uma por 3 horas a $127^{\circ} \mathrm{C}(1,5 \mathrm{~atm}$ de pressão), contida em bandejas plásticas $(56 \times 35 \times 10 \mathrm{~cm})$. As sementes foram distribuídas em orifícios individuais, eqüidistantes e a $3 \mathrm{~cm}$ de profundidade. Antes do fechamento dos orifícios, foi feita a inoculação com $R$. solani. Uma quantidade pré estabelecida do inóculo do patógeno foi misturada em $1 \mathrm{~kg}$ de areia, sendo esta mistura distribuída homogeneamente na superfície do substrato, de modo a cobrir todas as sementes, ficando em contato direto com as mesmas.

Para as avaliações de emergência inicial e final e de tombamento de pré e pós-emergência, foi utilizado o "growing on test". Para cada bandeja plástica contendo areia lavada, foram semeadas 200 sementes. Foram realizadas duas avaliações de emergência: a avaliação inicial (aos sete dias após a semeadura - 7 DAS) e a avaliação final (aos 26 DAS). A avaliação de tombamento foi realizada diariamente, a partir dos 7 DAS, computando-se o número de plântulas tombadas até os 26 DAS. Ao final desse período obteve-se um valor final cumulativo de plântulas tombadas. A avaliação de plântulas de algodoeiro com sintomas de tombamento, foi feita nas plântulas que não tombaram, ou seja, naquelas que estavam com sintomas típicos (lesões deprimidas no hipocótilo, de coloração marrom-avermelhada) por ocasião da avaliação do estande final. Para a confirmação do patógeno, plântulas com sintomas de "tombamento" foram coletadas, lavadas em água corrente, desinfestadas superficialmente com uma solução de hipoclorito de sódio a $1,5 \%$ por 3 minutos e posteriormente submetidas a uma "câmara úmida". Após cinco dias de incubação em estufas para $\mathrm{BOD}$, a $22^{\circ} \mathrm{C}$ e $12 \mathrm{~h}$ luz/12h escuro, foi realizada a leitura e identificação do patógeno.

Foi utilizado o delineamento experimental em esquema fatorial, inteiramente casualizado, com quatro repetições de 200 sementes, perfazendo um total de 800 sementes/tratamento. Para a análise de variância, os dados de percentagem foram transformados para arc sen $\sqrt{x / 100}$. As médias foram comparadas pelo teste de Duncan, ao 
nível de 5\% de probabilidade.

$\mathrm{O}$ tratamento fungicida, quando necessário, foi realizado colocandose os produtos sobre $500 \mathrm{~g}$ de sementes em sacos plásticos de $2,0 \mathrm{~L}$ e agitando-se o recipiente por alguns minutos até a completa cobertura das sementes pelos fungicidas.

Para garantir que os resultados revelem única e exclusivamente o efeito do fungo $R$. solani sobre a emergência e tombamento, foram utilizadas sementes livres de qualquer espécie de fungo (escolha baseada em resultados de vários testes de sanidade de sementes) que possa interferir nas avaliações.

Seis cultivares de algodoeiro (BRS Aroeira, BRS Ipê, BRS Cedro, CNPA ITA 90 II, DeltaOpal e Fibermax 966 ) foram avaliadas quanto à suscetibilidade a $R$. solani $\mathrm{AG}-4$ (isolado do fungo obtido de lesões do coleto de plântulas de algodoeiro provenientes de experimentos instalados na Embrapa Agropecuária Oeste, Dourados, MS). Foram definidas quatro densidades populacionais do fungo, com base na patogenicidade do inóculo inicial de $R$. solani, níveis estes ajustados em função da percentagem de tombamento observado, conforme metodologia proposta por Wang \& Davis (16) e Weinhold (17). Para cada cultivar e cada nível de inóculo do patógeno, foram semeadas 200 sementes/bandeja plástica/repetição, conforme descrito anteriormente.
Os benefícios do tratamento de sementes de algodoeiro com fungicidas para cada uma das seis cultivares, dentro de cada nível de inóculo do patógeno, também foi avaliado. Para tal, outras 200 sementes de cada cultivar foram tratadas com a mistura fungicida triadimenol+pencycuron+tolylfluanid $(50+50+30 \mathrm{~g}$ do i.a. $/ 100 \mathrm{~kg}$ de sementes) e semeadas nas mesmas condições descritas anteriormente.

As avaliações foram realizadas com base no desenvolvimento de sintomas e sobrevivência das plântulas, utilizando os dados de emergência inicial e final e de tombamento de pós-emergência, conforme descrito anteriormente.

Para cada cultivar, foi deixada uma testemunha sem inoculação, para fins comparativos.

\section{RESULTADOS E DISCUSSÃO}

O resultado da análise de variância mostrou efeito significativo das interações cultivares $\mathrm{x}$ níveis de inóculo, cultivares $\mathrm{x}$ fungicidas e níveis de inóculo x fungicidas (Tabelas 1 a 12) na emergência inicial e final de plântulas de algodoeiro bem como no tombamento de pós-emergência e na percentagem de plântulas com sintomas desta doença.

Tabela 1. Efeito de cultivares x níveis de inóculo de Rhizoctonia solani na emergência inicial de plântulas de algodoeiro.

\begin{tabular}{|c|c|c|c|c|}
\hline \multirow[b]{2}{*}{ Cultivares } & \multicolumn{4}{|c|}{ Níveis de inóculo de Rhizoctonia solani } \\
\hline & $\overline{\mathrm{Og}}$ & $1 \mathrm{~g}$ & $2 \mathrm{~g}$ & $3 g$ \\
\hline DeltaOpal & 90,0 a $\mathrm{A}$ & 92,0 a $\mathrm{A}$ & 86,5 b B & 79,0 с C \\
\hline Fibermax 966 & 77,5 с A & 77,8 с A & $71,8 \mathrm{~d} B$ & $70,5 \mathrm{~d} B$ \\
\hline CNPA ITA 90 II & 92,2 a A & 91,5 a $\mathrm{A}$ & 90,0 a $\mathrm{A}$ & 91,0 a $\mathrm{A}$ \\
\hline BRS IPE & 91,5 a $\mathrm{A}$ & 90,8 a $\mathrm{A}$ & 89,8 a $\mathrm{A}$ & 86,2 b B \\
\hline BRS CEDRO & 92,5 a $\mathrm{A}$ & 89,8 a $\mathrm{A}$ & 90,0 a $\mathrm{A}$ & $87,8 \mathrm{~b} \mathrm{~A}$ \\
\hline BRS AROEIRA & 85,8 b A & 81,8 b B & $79,8 \mathrm{c} \mathrm{B}$ & 81,2 c B \\
\hline Média & $88,2 \quad \mathrm{~A}$ & $87,3 \quad \mathrm{~A}$ & $84,6 \quad \mathrm{~B}$ & $82,6 \quad \mathrm{C}$ \\
\hline
\end{tabular}

Médias seguidas pela mesma letra minúscula nas colunas e maiúscula nas linhas não diferem significativamente entre si (Duncan, 5\%) C.V. (\%) = 10,37

Tabela 2. Efeito de cultivares x níveis de inóculo de Rhizoctonia solani na emergência final de plântulas de algodoeiro.

\begin{tabular}{|c|c|c|c|c|}
\hline \multirow{3}{*}{$\begin{array}{l}\text { Cultivares } \\
\text { DeltaOpal }\end{array}$} & \multicolumn{4}{|c|}{ Níveis de inóculo de Rhizoctonia solani } \\
\hline & $0 \mathrm{~g}$ & $\lg$ & $2 g$ & $3 g$ \\
\hline & 90,0 a $\mathrm{A}$ & 91,2 a $\mathrm{A}$ & 84,8 b B & $66,5 \mathrm{~d} \mathrm{C}$ \\
\hline Fibermax 966 & 77,5 c A & $76,8 \mathrm{c} \mathrm{A}$ & $70,2 \mathrm{~d} \mathrm{~B}$ & 58,0 e $\mathrm{C}$ \\
\hline CNPA ITA 90 II & 92,2 a $\mathrm{A}$ & 90,8 a $\mathrm{AB}$ & 89,2 a $\mathrm{B}$ & 87,0 a $\mathrm{C}$ \\
\hline BRS IPE & 91,5 a $\mathrm{A}$ & 90,0 a $\mathrm{A}$ & 89,0 a $\mathrm{A}$ & 79,2 b B \\
\hline BRS CEDRO & 92,5 a $\mathrm{A}$ & 88,5 a $\mathrm{B}$ & 88,2 a $\mathrm{B}$ & $81,5 \mathrm{~b} \mathrm{C}$ \\
\hline BRS AROEIRA & $85,8 \mathrm{~b} \mathrm{~A}$ & $81,8 \mathrm{~b} \mathrm{~B}$ & $78,2 \mathrm{c} \mathrm{C}$ & 77,5 с C \\
\hline Média & $88,2 \quad \mathrm{~A}$ & $86,5 \quad A$ & $83,3 \quad \mathrm{~B}$ & $75,0 \quad \mathrm{C}$ \\
\hline
\end{tabular}

Médias seguidas pela mesma letra minúscula nas colunas e maiúscula nas linhas não diferem significativamente entre si (Duncan, $5 \%)$ C.V. (\%) = 12,07

Tabela 3. Efeito de cultivares x níveis de inóculo de Rhizoctonia solani no tombamento de pós-emergência de plântulas de algodoeiro.

\begin{tabular}{|c|c|c|c|c|}
\hline \multirow[b]{2}{*}{ Cultivares } & \multicolumn{4}{|c|}{ Níveis de inóculo de Rhizoctonia solani } \\
\hline & $0 \mathrm{~g}$ & $\lg$ & $2 \mathrm{~g}$ & $3 g$ \\
\hline DeltaOpal & 0,0 a $\mathrm{C}$ & 0,6 c C & 2,4 a B & 17,5 a A \\
\hline Fibermax 966 & 0,0 a $\mathrm{C}$ & 1,7 a B & 2,2 a B & 18,0 a $\mathrm{A}$ \\
\hline CNPA ITA 90 II & 0,0 a $\mathrm{C}$ & 0,8 c B & $0,8 \mathrm{~b} \mathrm{~B}$ & $4,4 \mathrm{~d} \mathrm{~A}$ \\
\hline BRS IPE & 0,0 a $\mathrm{C}$ & 0,8 c B & $1,1 \mathrm{~b} \mathrm{~B}$ & $10,0 \mathrm{~b} \mathrm{~A}$ \\
\hline BRS CEDRO & 0,0 a $\mathrm{C}$ & $1,4 \mathrm{~b} \mathrm{~B}$ & 2,0 a B & $7,4 \mathrm{c} \mathrm{A}$ \\
\hline BRS AROEIRA & 0,0 a $\mathrm{C}$ & $0,0 \mathrm{~d} C$ & 2,0 a B & $4,3 \mathrm{~d} A$ \\
\hline Média & $0,0 \quad \mathrm{D}$ & $0,9 \quad \mathrm{C}$ & $1,8 \quad \mathrm{~B}$ & $10,3 \quad \mathrm{~A}$ \\
\hline
\end{tabular}

Médias seguidas pela mesma letra minúscula nas colunas e maiúscula nas linhas não diferem significativamente entre si (Duncan, $5 \%)$ C.V. $(\%)=15,82$ 
Tabela 4. Efeito de cultivares x níveis de inóculo de Rhizoctonia solani na percentagem de plântulas de algodoeiro com sintomas de tombamento.

\begin{tabular}{|c|c|c|c|c|}
\hline \multicolumn{5}{|c|}{ Níveis de inóculo de Rhizoctonia solani } \\
\hline Cultivares & $\overline{0 g}$ & $\lg$ & $2 \mathrm{~g}$ & $3 g$ \\
\hline DeltaOpal & 0,0 a $\mathrm{D}$ & $3,4 \mathrm{~b} \mathrm{C}$ & 8,6 a $\mathrm{B}$ & 17,6 a $\mathrm{A}$ \\
\hline Fibermax 966 & 0,0 a $\mathrm{D}$ & $2,4 \mathrm{c} \mathrm{C}$ & $6,6 \mathrm{~b} \mathrm{~B}$ & $12,0 \mathrm{~b} \mathrm{~A}$ \\
\hline CNPA ITA 90 II & 0,0 a $\mathrm{D}$ & $2,2 \mathrm{c} \mathrm{C}$ & $4,3 \mathrm{~d} B$ & $8,0 \mathrm{~d} A$ \\
\hline BRS IPE & 0,0 a $\mathrm{D}$ & 4,5 a C & 6,0 bc $\mathrm{B}$ & 10,9 с A \\
\hline BRS CEDRO & 0,0 a $\mathrm{D}$ & $1,8 \mathrm{~d} \mathrm{C}$ & 3,2 e $B$ & $10,3 \mathrm{c} \mathrm{A}$ \\
\hline BRS AROEIRA & 0,0 a $\mathrm{D}$ & $3,1 \mathrm{~b} \mathrm{C}$ & $5,6 \mathrm{c} \mathrm{B}$ & $8,0 \mathrm{~d} A$ \\
\hline Média & $0,0 \quad \mathrm{D}$ & $2,9 \quad \mathrm{C}$ & $5,7 \quad \mathrm{~B}$ & $\overline{11,1 \mathrm{~A}}$ \\
\hline
\end{tabular}

Médias seguidas pela mesma letra minúscula nas colunas e maiúscula nas linhas não diferem significativamente entre si (Duncan, $5 \%$ C.V. $(\%)=16,70$

Tabela 5. Efeito de cultivares x tratamento de sementes com fungicidas na emergência inicial de plântulas de algodoeiro.

\begin{tabular}{|c|c|c|}
\hline \multirow[b]{2}{*}{ Cultivares } & \multicolumn{2}{|c|}{ Tratamento das sementes com fungicidas } \\
\hline & Sementes tratadas & Sementes não tratadas \\
\hline DeltaOpal & 90,0 c A & 83,6 b B \\
\hline Fibermax 966 & 77,6 e $\mathrm{A}$ & $71,2 \mathrm{~d} B$ \\
\hline CNPA ITA 90 II & 94,1 a $\mathrm{A}$ & 88,2 a B \\
\hline BRS IPÊ & 91,9 bc A & 87,2 a B \\
\hline BRS CEDRO & $92,9 \mathrm{ab} \mathrm{A}$ & 87,2 a B \\
\hline BRS AROEIRA & $86,2 \mathrm{~d} A$ & $78,0 \mathrm{c} \mathrm{B}$ \\
\hline Média & $88,8 \quad \mathrm{~A}$ & $82,6 \quad \mathrm{~B}$ \\
\hline
\end{tabular}

Médias seguidas pela mesma letra minúscula nas colunas e maiúscula nas linhas não diferem significativamente entre si (Duncan, $5 \%$ C.V. $(\%)=11,22$

Tabela 6. Efeito de cultivares $\mathrm{x}$ tratamento de sementes com fungicidas na emergência final de plântulas de algodoeiro.

\begin{tabular}{|c|c|c|}
\hline \multirow[b]{2}{*}{ Cultivares } & \multicolumn{2}{|c|}{ Tratamento das sementes com fungicidas } \\
\hline & Sementes tratadas & Sementes não tratadas \\
\hline DeltaOpal & 89,6 c A & $76,6 \mathrm{~b} \mathrm{~B}$ \\
\hline Fibermax 966 & 77,2 e $A$ & 64,0 c B \\
\hline CNPA ITA 90 II & 94,0 a $\mathrm{A}$ & 85,6 a $\mathrm{B}$ \\
\hline BRS IPE & 91,5 bc $\mathrm{A}$ & 83,4 a B \\
\hline BRS CEDRO & $92,5 \mathrm{ab} A$ & 82,9 a $\mathrm{B}$ \\
\hline BRS AROEIRA & $86,0 \mathrm{~d} A$ & $75,6 \mathrm{~b} \mathrm{~B}$ \\
\hline Média & $88,5 \mathrm{~A}$ & $78,2 \quad \mathrm{~B}$ \\
\hline
\end{tabular}

Médias seguidas pela mesma letra minúscula nas colunas e maiúscula nas linhas não diferem significativamente entre si (Duncan, $5 \%)$ C.V. $(\%)=12,74$

Tabela 7. Efeito de cultivares x tratamento de sementes com fungicidas no tombamento de pós-emergência de plântulas de algodoeiro.

\begin{tabular}{|c|c|c|}
\hline \multirow[b]{2}{*}{ Cultivares } & \multicolumn{2}{|c|}{ Tratamento das sementes com fungicidas } \\
\hline & Sementes tratadas & Sementes não tratadas \\
\hline DeltaOpal & 0,4 a $\mathrm{B}$ & 9,8 a $\mathrm{A}$ \\
\hline Fibermax 966 & 0,5 a B & 10,4 a $\mathrm{A}$ \\
\hline CNPA ITA 90 II & 0,1 a B & $3,0 \mathrm{c} \mathrm{A}$ \\
\hline BRS IPE & 0,3 a B & $5,6 \mathrm{~b} \mathrm{~A}$ \\
\hline BRS CEDRO & 0,4 a B & $5,0 \mathrm{~b} \mathrm{~A}$ \\
\hline BRS AROEIRA & 0,3 a B & $2,8 \mathrm{c} \mathrm{A}$ \\
\hline Média & $0,3 \mathrm{~B}$ & $6,1 \quad \mathrm{~A}$ \\
\hline
\end{tabular}

Médias seguidas pela mesma letra minúscula nas colunas e maiúscula nas linhas não diferem significativamente entre si (Duncan, $5 \%)$ C.V. $(\%)=14,88$

Tabela 8. Efeito de cultivares x tratamento de sementes com fungicidas na percentagem de plântulas de algodoeiro com sintomas de tombamento.

\begin{tabular}{|c|c|c|}
\hline \multirow[b]{2}{*}{ Cultivares } & \multicolumn{2}{|c|}{ Tratamento das sementes com fungicidas } \\
\hline & Sementes tratadas & Sementes não tratadas \\
\hline DeltaOpal & 0,7 a B & 14,0 a A \\
\hline Fibermax 966 & 1,0 a B & $9,5 \mathrm{~b} \mathrm{~A}$ \\
\hline CNPA ITA 90 II & 0,8 a B & $6,7 \mathrm{~d} A$ \\
\hline BRS IPE & 0,8 a B & 7,4 c A \\
\hline BRS CEDRO & 1,0 a B & 7,0 c A \\
\hline BRS AROEIRA & 0,6 a B & $6,4 \mathrm{~d} \mathrm{~A}$ \\
\hline Média & $0,8 \quad \mathrm{~B}$ & $8,5 \quad \mathrm{~A}$ \\
\hline
\end{tabular}

Médias seguidas pela mesma letra minúscula nas colunas e maiúscula nas linhas não diferem significativamente entre si $($ Duncan, $5 \%)$ C.V. $(\%)=15,60$ 
Tabela 9. Efeito de níveis de inóculo x tratamento de sementes com fungicidas na emergência inicial de plântulas de algodoeiro.

\begin{tabular}{|c|c|c|}
\hline \multirow[b]{2}{*}{ Níveis de inóculo } & \multicolumn{2}{|c|}{ Tratamento das sementes com fungicidas } \\
\hline & Sementes tratadas & Sementes não tratadas \\
\hline $0 \mathrm{~g}$ & 91,2 a $\mathrm{A}$ & 85,3 a B \\
\hline $\lg$ & 90,1 a $\mathrm{A}$ & 84,5 a B \\
\hline $2 \mathrm{~g}$ & $87,0 \mathrm{~b} \mathrm{~A}$ & 82,2 b B \\
\hline $3 g$ & 86,9 b A & 78,3 c B \\
\hline Média & 88,8 A & $82,6 \quad \mathrm{~B}$ \\
\hline
\end{tabular}

Médias seguidas pela mesma letra minúscula nas colunas e maiúscula nas linhas não diferem significativamente entre si (Duncan, $5 \%$ ) C.V. (\%) = 14,82

Tabela 10. Efeito de níveis de inóculo $\mathrm{x}$ tratamento de sementes com fungicidas na emergência final de plântulas de algodoeiro.

\begin{tabular}{|c|c|c|}
\hline \multirow[b]{2}{*}{ Níveis de inóculo } & \multicolumn{2}{|c|}{ Tratamento das sementes com fungicidas } \\
\hline & Sementes tratadas & Sementes não tratadas \\
\hline $0 \mathrm{~g}$ & 91,2 a $\mathrm{A}$ & 85,3 a B \\
\hline $\lg$ & 87,3 b A & 82,9 b B \\
\hline $2 \mathrm{~g}$ & 86,5 b A & 80,1 b B \\
\hline $3 g$ & 86,2 b A & $63,8 \mathrm{c} \mathrm{B}$ \\
\hline Média & 87,8 A & $78,0 \quad \mathrm{~B}$ \\
\hline
\end{tabular}

Médias seguidas pela mesma letra minúscula nas colunas e maiúscula nas linhas não diferem significativamente entre si (Duncan, $5 \%$ ) C.V. ( $\%)=12,45$

Tabela 11. Efeito de níveis de inóculo x tratamento de sementes com fungicidas no tombamento de pós-emergência de plântulas de algodoeiro.

\begin{tabular}{|c|c|c|}
\hline \multirow[b]{2}{*}{ Níveis de inóculo } & \multicolumn{2}{|c|}{ Tratamento das sementes com fungicidas } \\
\hline & Sementes tratadas & Sementes não tratadas \\
\hline $0 \mathrm{~g}$ & 0,0 с A & $0,0 \mathrm{~d} A$ \\
\hline $1 \mathrm{~g}$ & 0,0 с B & $1,8 \mathrm{c} \mathrm{A}$ \\
\hline $2 \mathrm{~g}$ & $0,6 \mathrm{~b} \mathrm{~B}$ & $2,9 \mathrm{~b} \mathrm{~A}$ \\
\hline $3 g$ & 0,9 a B & 19,6 a $\mathrm{A}$ \\
\hline Média & $0,4 \quad \mathrm{~B}$ & $6,1 \mathrm{~A}$ \\
\hline
\end{tabular}

Médias seguidas pela mesma letra minúscula nas colunas e maiúscula nas linhas não diferem significativamente entre si (Duncan, $5 \%$ C.V. $(\%)=16,05$

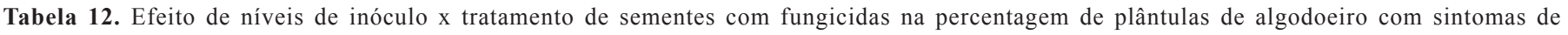
tombamento.

\begin{tabular}{|c|c|c|}
\hline \multirow[b]{2}{*}{ Níveis de inóculo } & \multicolumn{2}{|c|}{ Tratamento das sementes com fungicidas } \\
\hline & Sementes tratadas & Sementes não tratadas \\
\hline $0 \mathrm{~g}$ & 0,0 c A & $0,0 \mathrm{~d} A$ \\
\hline $\lg$ & $0,7 \mathrm{~b} \mathrm{~B}$ & 4,9 с A \\
\hline $2 g$ & 1,5 a B & $9,2 \mathrm{~b} \mathrm{~A}$ \\
\hline $3 g$ & 1,8 a B & 20,6 a A \\
\hline Média & $1,0 \quad \mathrm{~B}$ & $8,7 \mathrm{~A}$ \\
\hline
\end{tabular}

Médias seguidas pela mesma letra minúscula nas colunas e maiúscula nas linhas não diferem significativamente entre si (Duncan, 5\%)

C.V. $(\%)=13,90$

Analisando-se os resultados da interação cultivares $\mathrm{x}$ níveis de inóculo (Tabelas 1 a 4), observa-se que o comportamento das cultivares, com relação a emergência inicial e final de plântulas de algodoeiro, bem como no tombamento de pós-emergência e na percentagem de plântulas com sintomas desta doença, foi significativamente influenciado pelas diferentes populações de $R$. solani avaliadas no ensaio. Assim, de uma maneira geral e independente da cultivar utilizada, à medida que se aumentou a densidade de inóculo do patógeno, menores índices de emergência e maiores índices de doença foram observados. Observou-se ainda comportamento diferenciado de algumas cultivares com relação ao ataque do fungo $R$. solani, merecendo destaque os genótipos CNPA ITA 90 II e BRS Aroeira, seguidos de BRS Cedro. Estas cultivares diferiram significativamente das demais, apresentando menor incidência de tombamento e menor percentagem de plântulas com sintomas desta doença, demonstrando maior tolerância ao ataque de $R$. solani em comparação às demais, que apresentaram maior suscetibilidade ao patógeno.

Os resultados referentes à interação cultivares $\mathrm{x}$ tratamento de sementes com fungicidas (Tabelas 5 a 8), mostraram claramente a importância da utilização desta prática, independente da cultivar, em relação a emergência inicial e final de plântulas de algodoeiro, bem como no tombamento de pós-emergência e na percentagem de plântulas com sintomas desta doença. As melhores emergências e os menores índices de doença (tombamento e plântulas lesionadas), independente da cultivar, foram obtidos quando as sementes foram tratadas com a mistura tolylfluanid + pencycuron + triadimenol, em comparação aos resultados obtidos quando as sementes não foram tratadas. Porém, quando se comparam as cultivares entre si e na ausência do tratamento da sementes com fungicidas, em relação ao tombamento de pósemergência e a percentagem de plântulas com sintomas desta doença, observam-se diferenças significativas entre elas, com os menores índices de doença sendo obtidos para CNPA ITA 90 II E BRS Aroeira, seguidas de BRS Cedro e BRS Ipê, demonstrando maior tolerância destas cultivares ao ataque de $R$. solani.

Foi observado efeito significativo da interação entre níveis de inóculo x tratamento de sementes com fungicidas (Tabelas 9 a 12), 
sendo que as populações do patógeno influenciaram significativamente nos benefícios do tratamento de sementes, afetando diretamente os resultados referentes à emergência inicial e final de plântulas, bem como o tombamento de pós-emergência do algodoeiro e a percentagem de plântulas com sintomas da doença, demonstrando que a performance da mistura fungicida testada (tolylfluanid + pencycuron + triadimenol) foi melhor na presença dos níveis mais baixos de inóculo do fungo.

O fungo $R$. solani pode causar tombamento de pós-emergência, o que foi observado nas condições do presente ensaio. A avaliação da percentagem de emergência final de plântulas (26 DAS), reflete a eficiência dos fungicidas na proteção das mesmas contra o ataque de $R$. solani, bem como a capacidade de manutenção do estande, no sentido de evitar o tombamento de pós-emergência causado por este patógeno. $\mathrm{O}$ efeito drástico do patógeno pode ser claramente observado quando se comparam os resultados obtidos nas testemunhas com e sem inoculação.

Asmus et al. (1) e Goulart et al. (9), utilizando esta mesma metodologia de inoculação de $R$. solani, além de Wang \& Davis (16) e Menten \& Paradela (15), chegaram a resultados semelhantes, os quais observaram aumento na emergência e no controle do tombamento de plântulas causado por $R$. solani, quando as sementes de algodoeiro foram tratadas com fungicidas. Os resultados obtidos no presente trabalho, somados aos citados anteriormente, demonstram a exequibilidade dessa metodologia de inoculação do substrato com $R$. solani, para avaliar a eficiência do tratamento de sementes de algodoeiro com fungicidas no controle desse patógeno, bem como para estudos visando determinar a suscetibilidade de cultivares de algodoeiro a $R$. solani, em condições de casa de vegetação. Esse tipo de trabalho proporciona resultados altamente confiáveis, uma vez que se trabalha em condições controladas, com quantidades e pressões de inóculo preestabelecidos, que permitem avaliar com precisão e praticamente sem chances de escape, os benefícios do tratamento de sementes com fungicidas em função de diferentes populações de um determinado patógeno.

Com relação aos benefícios do tratamento de sementes de algodoeiro com fungicidas em relação ao potencial de inóculo de $R$. solani no solo, os resultados obtidos neste trabalho vêm corroborar com aqueles realizados nos EUA por Davis et al. (3), Garber et al. $(7,8)$, Wang \& Davis, (16) e por Goulart $(12,13)$ no Brasil, os quais demonstraram claramente a necessidade do uso do tratamento de sementes com fungicidas além de mostrar que a eficiência de um determinado produto está diretamente relacionada com a população de $R$. solani no solo. Observou-se ainda, melhor eficiência dos fungicidas frente às populações mais baixas do fungo no solo e que, na presença de maiores níveis de inóculo do patógeno, a eficácia dos mesmos reduz significativamente.

No presente estudo foram observadas diferentes respostas das cultivares testadas frente ao patógeno $R$. solani, sendo que até o momento, em se tratando do tombamento de plântulas causado por R. solani, não se conhecia nenhuma informação no Brasil que mostrasse o comportamento das cultivares disponíveis no mercado frente a ação desse patógeno. Nos USA, trabalhos desenvolvidos por Bush et al. (2), Garber et al. (6), Hefner (14) e Wang \& Davis (16) mostraram diferentes respostas de cultivares de algodoeiro a $R$. solani. No presente estudo, as cultivares CNPA ITA 90 II E BRS Aroeira, BRS Cedro e BRS Ipê apresentaram-se como as mais resistentes a $R$. solani, apesar das diferenças de performance destas cultivares terem sido geralmente pequenas, o que também foi observado por Wang \& Davis (16) para as cultivares DP 6100, CB 7 e Royale.
Os resultados obtidos demonstraram claramente que não se deve dispensar o tratamento das sementes de algodoeiro com fungicidas, apesar de algumas cultivares terem apresentado certa tolerância ao patógeno. Entretanto, como a performance de um determinado fungicida está relacionada, dentre outros fatores, com a população do patógeno no solo (conforme foi comprovado neste ensaio) e com a resistência do material a ser utilizado, sugere-se, em áreas com histórico de altas populações de $R$. solani, dar preferência às cultivares que apresentarem melhor comportamento frente ao patógeno, visando otimizar a eficácia do fungicida aplicado às sementes de algodoeiro. Deve-se considerar ainda que a obtenção desses resultados poderá contribuir para um melhor entendimento da biologia de $R$. solani, incluindo aí as relações entre populações e doença, comportamento de diferentes cultivares frente ao patógeno bem como o efeito do potencial de inóculo do fungo na eficácia do tratamento de sementes com fungicidas.

\section{REFERÊNCIAS BIBLIOGRÁFICAS}

1. Asmus, G.L.; Goulart, A.C.P.; Paiva, F. de A. Eficiência de alguns fungicidas usados em tratamento de sementes de algodoeiro no controle do tombamento causado por Rhizoctonia solani. Fitopatologia Brasileira, Brasília, DF, v.18, Suplemento, p.298, 1993.

2. Bush, D.L.; Bird, L.S.; Bourland, F.M. Variation in susceptibility to Rhizoctonia solani among MAR cotton cultivars. In: Beltwide Cotton Production Research Conferences, 1978. Proceedings... Memphis: National Cotton Council, 1978. p.21.

3. Davis, R.M.; Nunez, J.J.; Subbarao, K.V. Benefits of cotton seed treatments for the control of seedling diseases in relation to inoculum densities of Pythium species and Rhizoctonia solani. Plant Disease, St. Paul, v.81, n.7, p.766-768, 1997.

4. Devay, J.E.; Garber, R.H.; Wakeman, R.J. Cotton seedling responses in greenhouse tests to combinations of chemical seed treatment for control of Pythium ultimum, Rhizoctonia solani, and Thielaviopsis basicola. In: Beltwide Cotton Production Research Conferences, 1980. Proceedings... Memphis: National Cotton Council, 1980. p.19.

5. Freira, E.C.; Farias, J.C.F. Cultivares de algodoeiro para o CentroOeste. In: Algodoeiro: tecnologia de produção. Dourados; Embrapa Agropecuária Oeste; Campina Grande: Embrapa Algodoeiro, 2001. p.159-180.

6. Garber, R.H.; Devay, J.E.; Wakeman, R.J.; Vargas, L. The role of cultivar tolerance in cotton seedling disease control. In: Beltwide Cotton Conferences, 1991, San Antonio. Proceedings... Memphis: National Cotton Council, 1991. v.1, p.163-165. Disponível em: <http://www.cotton.org/beltwide/proceedings $>$. Acesso em: 6 out. 2004.

7. Garber, R.H.; Devay, J.E.; Weinhold, A.R.; Matheron, D. Relationship of pathogen inoculum to cotton seedling disease control with fungicides. Plant Disease Reporter, Beltsville, v.63, n.3, p.246-250, 1979 .

8. Garber, R.H.; Devay, J.E.; Weinhold; A.R.; Wakeman, R.J. Pathogen inoculum a key factor in fungicide seed treatment efficiency. In: Beltwide Cotton Production Research Conferences, 1980. Proceedings... Memphis: National Cotton Council, 1980. p.19.

9. Goulart, A.C.P.; Andrade, P.J.M.; Borges, E.P. Controle do tombamento de plântulas do algodoeiro causado por Rhizoctonia solani pelo tratamento de sementes com fungicidas. Summa Phytopathologica, Jaboticabal, v.26, n.3, p.362-368, 2000.

10. Goulart, A.C.P.; Melo Filho, G.A. de. Quanto custa tratar as sementes de soja, milho e algodoeiro com fungicidas? Dourados: Embrapa Agropecuária Oeste, 2000. 31p. (Boletim de Pesquisa, 7).

11. Goulart, A.C.P. Tratamento de sementes do algodoeiro com fungicidas. In: Algodoeiro: tecnologia de produção. Dourados: Embrapa Agropecuária Oeste; Campina Grande: Embrapa Algodoeiro, 2001. p.140-158. 
12. Goulart, A.C.P. Benefícios do tratamento de sementes de algodoeiro com fungicidas no controle do tombamento em relação à densidade de inóculo de Rhizoctonia solani. Fitopatologia Brasileira, Brasília, DF, v.27, Suplemento, p.218, 2002.

13. Goulart, A.C.P. Influência da densidade de inóculo de Rhizoctonia solani na eficiência do tratamento de sementes de algodoeiro com fungicidas no controle do tombamento. In: Congresso Brasileiro Do Algodoeiro, 4., 2003, Goiânia. Algodão: um mercado em evolução: anais. Campina Grande: Embrapa Algodoeiro: Fundação GO, 2003. (Documentos, 118). CDROM.

14. Hefner, J.J. Screening cotton for resistance to damping-off by
Rhizoctonia solani. In: Beltwide Cotton Production Research Conferences, 1968. Proceedings... Memphis: National Cotton Council, 1968. p.164-165.

15. Menten, J.O.M.; Paradela, A.L. Tratamento químico de sementes de algodoeiro para controle de Rhizoctonia solani. Summa Phytopathologica, Jaboticabal, v.22, n.1, p.60, 1996.

16. Wang, H.; Davis, R.M. Susceptibility of selected cotton cultivars to seedling disease pathogens and benefits of chemical seed treatments. Plant Disease, St. Paul, v.18, n.9, p.1085-1088, 1997.

17. Weinhold, A.R. Population of Rhizoctonia solani in agricultural soils determined by a screening procedure. Phytopathology, St. Paul, v.67, p.566-569, 1977. 